(2) Open Access Full Text Article

REVIEW

\title{
A review of sitagliptin with special emphasis on its use in moderate to severe renal impairment
}

This article was published in the following Dove Press journal:

Drug Design, Development and Therapy

29 August 2013

Number of times this article has been viewed

\author{
Vinay S Eligar' \\ Stephen C Bain ${ }^{2}$ \\ 'University Hospital of Wales, Cardiff, \\ UK; ${ }^{2}$ Singleton Hospital, Swansea \\ University, Swansea, UK
}

\begin{abstract}
Sitagliptin is the first dipeptidylpeptidase-4 inhibitor to be used in the management of type 2 diabetes. It is widely used as an add-on therapy to ongoing management or as monotherapy where it is deemed necessary. It has been found to be beneficial in improving $\beta$-cell function and glycemic control, and also is used in special circumstances like chronic kidney disease, with appropriate dose reductions. Overall, cardiovascular outcomes are no different from other oral hypoglycemic agents. In this review article we have summarized all the previous studies relevant to sitagliptin use in clinical practice and emphasized its use in various stages of chronic kidney disease.
\end{abstract}

Keywords: sitagliptin, CKD, chronic kidney disease, renal impairment

\section{Introduction}

Current estimates suggest that by 2030 the worldwide prevalence of diabetes will be 336 million. In the UK, 3 million people ${ }^{1}$ are currently diagnosed with diabetes, and the numbers are set to rise. A UK-based study showed that diabetes prevalence increased from $2.8 \%$ in 1996 to $4.3 \%$ in 2005 , predominantly due to an increase in type 2 diabetes mellitus (T2DM). ${ }^{2}$ In the US, about 18.8 million people have diabetes, and it is estimated that 7.0 million people are undiagnosed - this equates to $8.3 \%$ of the population. ${ }^{3}$

The aim of treatment in managing diabetes is to achieve good glycemic control and to reduce microvascular and macrovascular complications of diabetes. Apart from lifestyle modifications and dietary intervention, metformin is the first-line medical therapy in T2DM. ${ }^{4,5}$ Other agents like sulfonylurea, thiazolidinedione, $\alpha$-glucosidase inhibitors, dipeptidylpeptidase-4 (DPP-4) inhibitors, glucagon-like peptide-1 (GLP-1) analogs, and insulin are used based upon individual requirements. This practice will probably change if early introduction of newer agents like DPP-4 inhibitors and GLP-1 analogs are demonstrated to achieve greater metabolic benefit in future studies. Pivotal studies like the Diabetes Control and Complications Trial (DCCT), Epidemiology of Diabetes Interventions and Complications (EDIC) study, and United Kingdom Prospective Diabetes Study (UKPDS) have demonstrated benefits of achieving lower glycated hemoglobin $\left(\mathrm{HbA}_{1 \mathrm{c}}\right)$. Recently, the Action in Diabetes and Vascular Disease: Preterax and Diamicron Modified Release Controlled Evaluation (ADVANCE) trial and the Action to Control Cardiovascular Risk in Diabetes (ACCORD) trial showed that intensive glycemic control reduced development of macroalbuminuria. ${ }^{6}$ The major risk of intensive management is hypoglycemia. Attaining ideal control without any
Correspondence: Vinay S Eligar University Hospital of Wales, Heath Park, Cardiff CFI4 4XW, UK Tel +44 780 9l 8031

Email eligarvs@gmail.com 
hypoglycemia is a challenge. The presence of complications such as nephropathy further increases the hypoglycemia risk. Diabetic nephropathy also mandates the reduction or withdrawal of certain therapeutic agents. Recent studies have demonstrated a low risk of hypoglycemia with DPP-4 inhibitors in the absence of concomitant use of sulfonylureas or insulin. It has also found that appropriate dose reductions with sitagliptin and saxagliptin allow for their use in chronic kidney disease (CKD) stage 1-5 and end-stage renal disease (ESRD) on hemodialysis. Further to this, the improvements in $\beta$-cell function shown in the studies until now are also an advantage that can be derived by early use of sitagliptin.

\section{CKD and diabetes}

Several studies have established that diabetes is associated with a significantly increased risk for CKD. ${ }^{7-11}$ More recently, a UK-based study ${ }^{12}$ indicated that diabetes increases the risk of developing moderate to severe CKD (stages 3b, 4, and 5). In women, the risk was about eight times higher and in men over 12 times higher compared with those without diabetes.

Kidney failure is the final stage of CKD, and each year in the US more than 100,000 people are diagnosed with kidney failure or ESRD. Diabetes is the most common cause of ESRD, accounting for nearly $44 \%$ of new cases. ${ }^{13} \mathrm{CKD}$ is now defined according to the parameters shown in Table 1.

Recently, there has been a wide debate regarding CKD classification. Following a collaborative meta-analysis and international conference by the organization Kidney Disease: Improving Global Outcomes (KDIGO), new recommendations for including clinical diagnosis and albuminuria stages, in addition to estimated glomerular filtration rate (eGFR) stages, are proposed. Tonelli et $\mathrm{al}^{14}$ have presented the new classification, integrating the new recommendations, which will help in making clinical decisions in order to improve patient outcomes.

Managing diabetes in the presence of CKD poses challenges, as CKD independently increases cardiovascular risk and mortality rates. The health burden in terms of cost of managing $\mathrm{CKD}$ and ESRD requiring renal replacement therapy is enormous. The goal is optimal glycemic control tailored to the patient. The availability of newer incretin-based therapies over the past 6 years has given a new dimension and opportunity in effective management of diabetes and associated metabolic syndrome. The management of T2DM in the presence of CKD is challenging. The risk of hypoglycemia and drug accumulation means that the choice of antidiabetic agents is narrowed, and dose reduction is advised. Making judicious use of newer therapies will help achieve better glycemic control and lower the complication rates. DPP-4 inhibitors have been licensed for use in this situation, even in CKD stage 3 , stage 4 , or stage 5 (ESRD) on hemodialysis. The pharmacokinetics of various DPP-4 inhibitors is different, and their suitability in CKD is variable. It is found that appropriate dose reductions with sitagliptin and saxagliptin allow for their use in all stages of CKD and ESRD on hemodialysis. Linagliptin is the only DPP-4 inhibitor licensed to be used without any dose reduction.

\section{$\beta$-cell dysfunction and development of diabetes}

T2DM is of multifactorial origin. The pathogenesis is complex and results from disturbance in insulin secretion, hepatic glucose production, and insulin resistance. Insulin is released from $\beta$-cells of the pancreas in a glucose-dependent manner via the action of incretins (GLP-1, gastric inhibitory peptide) secreted in response to oral carbohydrate. Obesity, insulin resistance, and genetic predisposition lead to disturbances in glucose regulation. The inadequate uptake of glucose from peripheral tissues leads to hyperglycemia and compensatory insulin hypersecretion from islet cells. Over a prolonged period of time, overburdened $\beta$-cells begin to dysfunction, and glycemic control worsens, leading to diabetes. The UKPDS has clearly demonstrated the progressive nature of $\beta$-cell dysfunction and the increasing need to add on further agents after a few years of treatment with sulfonylureas. Therapies that aim to conserve $\beta$-cells and protect them would be ideal in preventing progression of diabetes. Incretin-based treatment has been shown to be effective in protecting and preserving $\beta$-cell function in animal models. Experimental studies on diabetic mice models have also demonstrated improvement in islet cell mass, which means DPP-4 inhibitors may prevent $\beta$-cell dysfunction. However, this is still unproven in humans. ${ }^{16-19}$

The human pancreas has pancreatic progenitor cells with the potential to transform into islet cells. In animal studies, diabetic mice treated with sitagliptin showed significant improvements in fasting glucose, $\mathrm{HbA}_{1 \mathrm{c}}$, islet cell mass, and ratio of pancreatic $\alpha$-cells to $\beta$-cells. In contrast, the diabetic mice models treated with glipizide showed improved glycemic control in early weeks only and had no beneficial effects on glucagon or fasting glucose. ${ }^{16,18}$

Transgenic mice with $\beta$-cell overexpression of human islet amyloid polypeptide, reduced $\beta$-cell mass, and altered islet cell topography showed improvements in islet cell topography and improved glucose-induced insulin 
Table I Risk categories for kidney and mortality outcomes, by estimated glomerular filtration rate (eGFR) and albuminuria or proteinuria stage

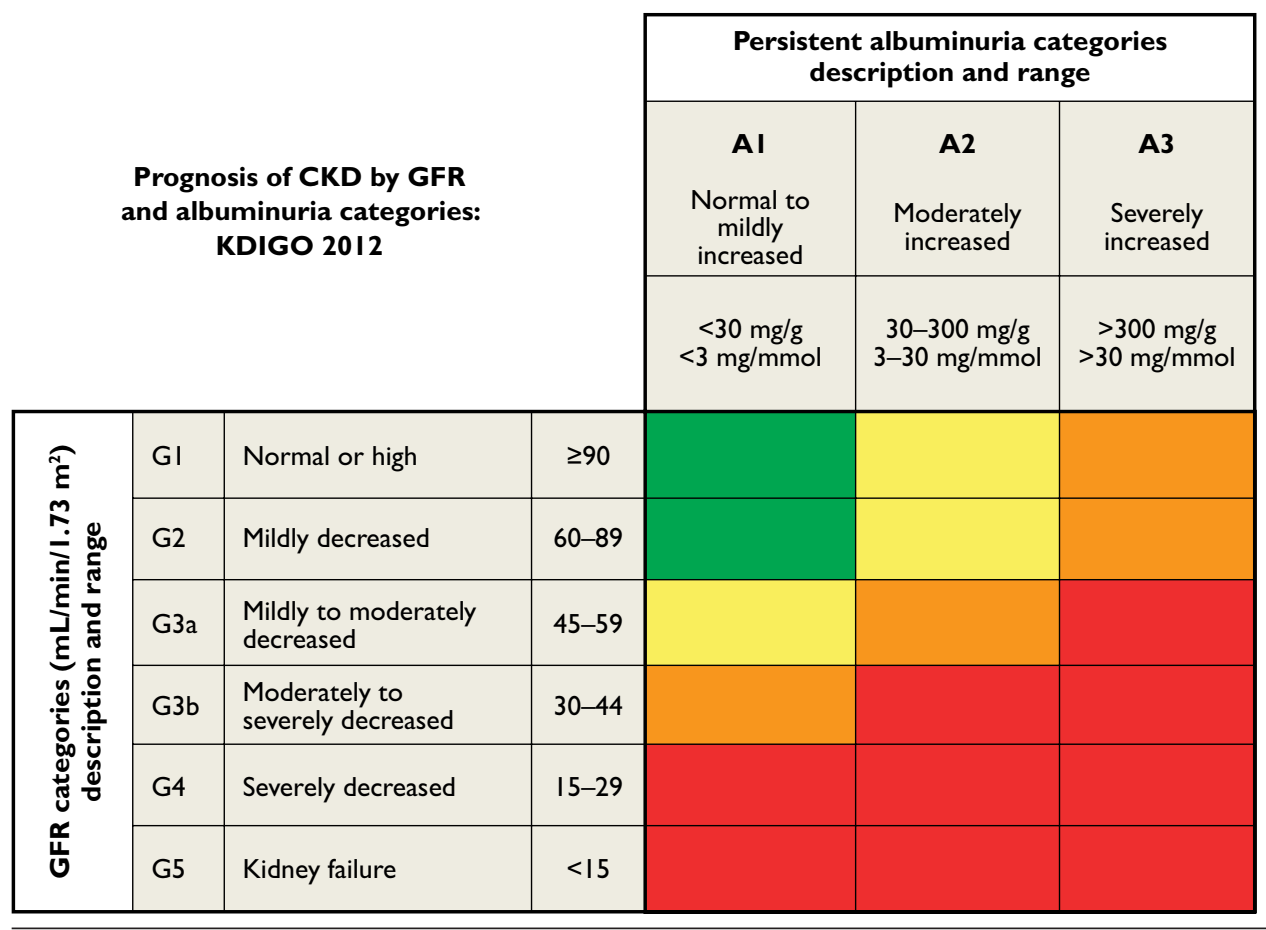

Notes: Green indicates low risk (if no other markers of kidney disease, no CKD); yellow indicates moderately increased risk; orange indicates high risk; red indicates very high risk. Reprinted with permission from Macmillan Publishers Ltd: Kidney Int Suppl. 2013;3:I-I50. Kidney Disease Improving Global Outcomes (KDIGO). 20I2 clinical practice guidelines for the evaluation and management of chronic kidney disease. Copyright $(\subset) 2013 .^{15}$

Abbreviation: CKD, chronic kidney disease.

response following treatment with another DPP-4 inhibitor (vildagliptin). ${ }^{19}$

Williams-Herman et $\mathrm{al}^{20}$ also showed that 24 weeks of initial treatment with sitagliptin or metformin monotherapy improved $\beta$-cell function. Furthermore, the combination of the two agents showed greater improvements than the individual monotherapies.

Various clinical trials have evaluated changes in markers of $\beta$-cell function as part of their outcomes. Sitagliptin has shown encouraging results with improvements in baseline fasting glucose, insulin, C-peptide, and glucagon levels; homoeostasis model assessment: insulin resistance (HOMAIR) and $\beta$-cell function (HOMA- $\beta$ ); and insulinogenic index (defined as 30-0 min insulin/30-0 min glucose). The biggest improvements are seen in recently diagnosed T2DM, as the $\beta$-cell function is not exhausted, in contrast to patients with many years of insulin resistance and hyperglycemia. Brazg et $\mathrm{al}^{17}$ conducted a trial of the effect of sitagliptin when added on to ongoing metformin therapy. The trial group received sitagliptin $50 \mathrm{mg}$ twice daily for 4 weeks followed by placebo, or vice versa. Sitagliptin treatment reduced 24-hour mean weighted plasma glucose. Fasting glucose and C-peptide levels also improved, suggesting a positive effect on $\beta$-cell function. Hence, markers of $\beta$-cell function (HOMA- $\beta$ and proinsulin/insulin ratio) were improved with sitagliptin treatment. ${ }^{21,22}$ This is an important aspect of treatment in T2DM, as it directly targets one of the major causes of the pathogenesis in T2DM. Hence, DPP-4 inhibitors have shown promising results in these initial studies. However, long-term studies specifically looking into improved $\beta$-cell function will be needed to ascertain whether the beneficial effect of DPP-4 persists beyond the initial years of treatment.

\section{Incretin-based therapy}

In the last 6 years, incretin-based treatment has contributed to reshaping the paradigm for the management of T2DM. GLP-1 is a gut hormone produced by L-cells present in the small intestine. It is released in response to ingestion of food and exerts its effects to regulate glucose utilization. It acts by glucose-dependent insulin release, delayed gastric emptying, and inhibition of glucagon production. ${ }^{23-25}$ The net effect is reduction in postprandial hyperglycemia due to glucose-dependent insulin release and suppression of glucagon production, leading to less hepatic glycolysis. In this way, it helps in regulating postprandial plasma glucose excursions and fasting hyperglycemia. GLP-1 
is susceptible to dipeptidyl peptidase-4 (DPP-4) enzymatic destruction, which renders it inactive within a few minutes of its release. Exogenous GLP-1 analogs such as exenatide, lixisenatide, and liraglutide are resistant to the DPP-4 enzyme and have proven beneficial in managing obese T2DM patients. Pharmacotherapy aimed at inhibiting DPP-4 prolongs the action of endogenous GLP-1 and thus improves glycemic control.

\section{DPP-4 inhibitors}

Gliptins (sitagliptin, vildagliptin, saxagliptin, alogliptin, and linagliptin) are oral incretin-based therapies. They are licensed for use as monotherapy or in combination with sulfonylureas, metformin, thiazolidinediones, and insulin. DPP-4 inhibitors bind to the catalytic site of the DPP-4 molecule and prevent the enzymatic degradation and inactivation of endogenous GLP-1. ${ }^{26}$

The past 5 years of clinical experience with sitagliptin (the first approved DPP-4 inhibitor) has proved it to be well tolerated and safe. ${ }^{27-29}$ Several studies have demonstrated a reduction in $\mathrm{HbA}_{1 \mathrm{c}}$ of up to $1 \%$, and they are weight neutral. Most of the studies have not specifically looked into the effect of sitagliptin on elderly populations. With the increasing numbers of elderly people who also have T2DM, we will eventually need specific studies involving this group. At the moment, the beneficial effects seen in younger populations are extrapolated into the elderly group, and treatment indications and goals remain unchanged.

The most common side effects of gliptins are upper respiratory tract infections, headaches, and nasopharyngitis. Very rarely, severe side effects including renal failure and rhabdomyolysis have been noted; however, these are rare enough to be published as isolated case reports.

\section{Sitagliptin}

Sitagliptin was the first DPP-4 inhibitor used in clinical practice. It is a phosphate monohydrate and is described chemically as 7-[(3R)-3-amino-1-oxo-4-(2,4,5-trifluorophenyl)butyl]-5,6,7,8-tetrahydro-3-(trifluoromethyl)-1,2,4triazolo[4,3-a]pyrazine phosphate $(1: 1)$ monohydrate. ${ }^{30}$ It has high affinity for the DPP-4 enzyme and it reaches steady plasma concentrations after 3 days of administration. After oral administration of a single dose, it is absorbed with maximum plasma levels reached in 1-2 hours and has a half-life of 12 hours. It has $87 \%$ bioavailability after a single oral dose of $100 \mathrm{mg} .{ }^{26}$ Pharmacokinetic studies have shown that sitagliptin achieved an inhibition of $80 \%$ of DPP-4 enzyme after a single dose of $100 \mathrm{mg}$, and its effect lasted for more than 24 hours. It increased the plasma GLP-1 levels by twofold compared with placebo. ${ }^{31}$

A study by Vincent et $\mathrm{al}^{33}$ demonstrated that after a single dose of radiolabelled sitagliptin orally, the majority of sitagliptin (87\%) was excreted unchanged in urine. It is excreted through both glomerular filtration and secretion into tubules. The remainder is metabolized by CYP 3A4 and CYP 2C8 enzymes and excreted in feces. In doses of 50-200 mg/day, more than $80 \%$ of DPP-4 enzyme is inhibited. This enables a two- to three-fold increase in endogenous GLP-1, thus augmenting its insulinotropic and glucagon-inhibiting effects. ${ }^{26,32-35}$

Sitagliptin has been shown to provide effective fasting and postprandial glycemic control in a wide range of patients with T2DM. Markers of $\beta$-cell function (HOMA- $\beta$ and proinsulin/insulin ratio) are also improved with sitagliptin treatment. ${ }^{21,22}$ The data until now have shown a significantly lower incidence of hypoglycemia with sitagliptin where used as monotherapy or as add-on to nonhypoglycemiacausing oral agents. However, when combined with a sulfonylurea, the risk of hypoglycemia increases to $12 \%$, as opposed to $1.8 \%$ with monotherapy. ${ }^{36}$ Vilsbøll et $\mathrm{al}^{37}$ have reported increased incidence of hypoglycemia (16\%) when sitagliptin is added to insulin in comparison with placebo $(8 \%)$ and insulin.

\section{Clinical trials with sitagliptin Sitagliptin monotherapy}

As the first DPP-4 inhibitor available for treatment, sitagliptin has been extensively trialed and has proven effective and safe (see Table 2). The trials have been carried out in most population groups, and results have been unequivocal in demonstrating a significant reduction in $\mathrm{HbA}_{1 \mathrm{c}}$ with minimal adverse events. Sitagliptin can be initiated as first line in patients intolerant to metformin and who need only a modest decrease in $\mathrm{HbA}_{1 \mathrm{c}}$ to achieve target control. The advantages are a low risk of hypoglycemia, weight neutrality, and a possible improvement in $\beta$-cell dysfunction.

Aschner et $\mathrm{al}^{38}$ conducted a randomized, double-blind, placebo-controlled study in which 741 patients with a mean baseline $\mathrm{HbA}_{1 \mathrm{c}}$ of $8.0 \%$ were allocated to sitagliptin $100 \mathrm{mg}$ or $200 \mathrm{mg}$ or placebo for 24 weeks. Sitagliptin $100 \mathrm{mg}$ and $200 \mathrm{mg}$ showed significant reductions in $\mathrm{HbA}_{1 \mathrm{c}}$ of $-0.79 \%$ and $-0.94 \%$, respectively, in comparison with placebo. Fasting and 2-hour postprandial glucose were also reduced in the sitagliptin group. There was no significant hypoglycemia and no change in baseline body weight with sitagliptin. Patients with higher baseline $\mathrm{HbA}_{1 \mathrm{c}}$ showed the 
Table 2 Summary of sitagliptin trials (all doses are in milligrams [mg])

\begin{tabular}{|c|c|c|c|c|c|}
\hline Trial & Number & $\begin{array}{l}\text { Duration } \\
\text { in weeks }\end{array}$ & Intervention & $\begin{array}{l}\text { Reduction glycated } \\
\text { hemoglobin (\%) }\end{array}$ & Comments \\
\hline \multirow[t]{2}{*}{ Aschner et $\mathrm{al}^{38}$} & 741 & 24 & SI00 & -0.79 & $\beta$-cell function improved \\
\hline & & & S200 & -0.94 & \\
\hline \multirow[t]{2}{*}{ Raz et $\mathrm{al}^{39}$} & 521 & 18 & SI00 & -0.60 & $\beta$-cell function improved \\
\hline & & & S200 & -0.48 & \\
\hline \multirow[t]{4}{*}{ Scott et al ${ }^{40}$} & 743 & 12 & S2.5 od & Reductions in all groups & Maximum reduction \\
\hline & & & SI 2.5 od & & with $50 \mathrm{mg}$ bid \\
\hline & & & S25 od & & \\
\hline & & & S50 bid & & \\
\hline \multirow[t]{4}{*}{ Goldstein et $\mathrm{al}^{41}$} & $|, 09|$ & 24 & $\mathrm{~S} 100$ & -0.83 & Additive hypoglycemic effect \\
\hline & & & $\mathrm{SI} 00+\mathrm{MI} 000$ & -1.57 & with combination therapy \\
\hline & & & $\mathrm{S} 100+\mathrm{M} 2000$ & -2.07 & \\
\hline & & & MI000 & -0.99 & \\
\hline Nonaka et al ${ }^{43}$ & 151 & 12 & SI00 & -0.65 & $\begin{array}{l}\text { Significantly reduced 2-hour } \\
\text { postprandial glucose }\end{array}$ \\
\hline Mohan et al ${ }^{44}$ & 530 & 18 & SI00 & -1.0 & $\begin{array}{l}\text { Significantly reduced 2-hour } \\
\text { postprandial glucose }\end{array}$ \\
\hline Charbonnel et $\mathrm{a}^{47}$ & 701 & 24 & $\begin{array}{l}M \geq I, 500 \\
\text { Add on } S I 00\end{array}$ & -0.65 & $\beta$-cell function improved \\
\hline \multirow[t]{4}{*}{ Scott el al ${ }^{48}$} & 273 & 18 & $M \geq 1,500$ & -0.73 & $>3 \mathrm{~kg}$ weight gain in $21 \%$ \\
\hline & & & Add on SIO0 & & glitazone-treated group vs $2 \%$ \\
\hline & & & $M \geq 1,500$ & -0.79 & sitagliptin group \\
\hline & & & Add on R8 & & \\
\hline \multirow[t]{4}{*}{ Nauck et a ${ }^{49}$} & $\mathrm{I}, \mathrm{I} 72$ & 52 & $M \geq 1500$ & -0.67 & Hypoglycemia rate was $5 \%$ \\
\hline & & & Add on SIO0 & & with sitagliptin vs $32 \%$ in \\
\hline & & & $M \geq 1500$ & -0.67 & glipizide group \\
\hline & & & Add on GL5-20 & & \\
\hline \multirow[t]{4}{*}{ Pérez-Monteverde et $\mathrm{a}^{52}$} & 492 & I8 phase $A$ & SI00 & -1.0 & Weight reduction with $S+M$ \\
\hline & & 28 phase $B$ & PI5-30 & -0.9 & \\
\hline & & & $S+M(50 / 1000$ bid $)$ & -1.7 & \\
\hline & & & P45 & -1.4 & \\
\hline \multirow[t]{4}{*}{ Hermansen et al ${ }^{36}$} & 441 & 24 & $\mathrm{Gm}+\mathrm{M}$ & -0.89 & Higher incidence of hypoglycemia \\
\hline & & & Add on SIOO & & when sitagliptin is added to \\
\hline & & & $\mathrm{Gm}$ & -0.57 & sulfonylurea \\
\hline & & & Add on SI00 & & \\
\hline \multirow[t]{2}{*}{ Rosenstock et a ${ }^{54}$} & 175 & 24 & P30-45 & -0.70 & Well tolerated \\
\hline & & & Add on SIO0 & & Low risk of hypoglycemia \\
\hline \multirow[t]{2}{*}{ Fonseca et al ${ }^{56}$} & 313 & 26 & $M \geq 1500+P \geq 30$ & 0.70 & Well tolerated \\
\hline & & & Add on SI00 & & Low risk of hypoglycemia \\
\hline \multicolumn{6}{|c|}{ Sitagliptin use in chronic kidney disease } \\
\hline Chan et $\mathrm{al}^{59}$ & 91 & 54 & S25-50 & -0.70 & $\begin{array}{l}\text { Well tolerated in chronic renal } \\
\text { impairment }\end{array}$ \\
\hline \multirow[t]{2}{*}{ Arjona Ferreira et al ${ }^{100}$} & 426 & 54 & $S 25-50$ & Sitagliptin noninferior & Higher hypoglycemia risk with \\
\hline & & & GL2.5-20 & to glipizide & glipizide \\
\hline \multirow[t]{2}{*}{ Arjona Ferreira et $\mathrm{a}^{61}$} & 129 & 54 & S25 & -0.72 & Well tolerated \\
\hline & & & GL2.5-20 & -0.89 & $\begin{array}{l}\text { Low risk of hypoglycemia } \\
\text { compared with glipizide }\end{array}$ \\
\hline
\end{tabular}

Abbreviations: bid, twice daily; GL, glipizide; Gm, glimepiride; M, metformin; od, once daily; P, pioglitazone; R, rosiglitazone; S, sitagliptin.

best reductions in $\mathrm{HbA}_{1 \mathrm{c}}$ levels. The study also showed that $\beta$-cell function and proinsulin/insulin ratio improved whilst on sitagliptin therapy.

Raz et $\mathrm{al}^{39}$ assessed the efficacy of sitagliptin in drugnaïve T2DM patients with $\mathrm{HbA}_{1 \mathrm{c}}$ of $\geq 7 \%$ to $\geq 10 \%$. A total of 521 patients with a mean baseline of $\mathrm{HbA}_{1 \mathrm{c}} 8.1 \%$ were randomized in a 1:2:2 ratio to treatment with placebo, sitagliptin $100 \mathrm{mg}$ once daily, or sitagliptin $200 \mathrm{mg}$ once daily for a study duration of 18 weeks. The $\mathrm{HbA}_{1 \mathrm{c}}$ reductions were $-0.60 \%$ and $-0.48 \%$ with sitagliptin $100 \mathrm{mg}$ and $200 \mathrm{mg}$, respectively. Those patients with higher baseline $\mathrm{HbA}_{1 \mathrm{c}}$ once again showed the maximum reductions in 
$\mathrm{HbA}_{1 \mathrm{c}}$ levels. The study also showed that $\beta$-cell function and proinsulin/insulin ratio improved whilst on sitagliptin therapy. Sitagliptin remained weight neutral.

Scott et $\mathrm{al}^{40}$ assessed the efficacy of sitagliptin in 743 treatment-naïve T2DM patients in a randomized, double-blind, placebo- and active-controlled study. Patients were randomized to one of the six treatment arms (placebo, sitagliptin $5 \mathrm{mg}$ once daily, $12.5 \mathrm{mg}$ once daily, $25 \mathrm{mg}$ once daily, or $50 \mathrm{mg}$ twice a day, or a titrating dose of glipizide 5-20 mg/day) for 12 weeks. The mean baseline $\mathrm{HbA}_{1 \mathrm{c}}$ of $7.9 \%$ improved in sitagliptin-treated patients by $-0.38 \%$ to $-0.77 \%$ in a dose-dependent manner (the highest reduction was in the sitagliptin $50 \mathrm{mg}$ twice-daily group) in comparison with placebo. The glipizide group showed a $-1 \%$ reduction in $\mathrm{HbA}_{1 \mathrm{c}}$. However, hypoglycemia was significantly higher in the glipizide group (17\%) compared with the sitagliptin group (2\%). As in other studies, sitagliptin was well tolerated and weight neutral.

Goldstein et $\mathrm{a}^{41}$ assessed the efficacy and safety of initial combination therapy with sitagliptin and metformin in 1,091 treatment-naïve patients with T2DM. Of the six treatment arms, one of them was sitagliptin $100 \mathrm{mg}$ once daily, and two were combinations of sitagliptin $100 \mathrm{mg}$ with either metformin $1000 \mathrm{mg}$ or $2000 \mathrm{mg}$. The remaining groups were metformin $1000 \mathrm{mg}$ /day or metformin $2000 \mathrm{mg} /$ day or placebo. The mean baseline $\mathrm{HbA}_{1 \mathrm{c}}$ was $7.5 \%-11 \%$. After 24 weeks, $\mathrm{HbA}_{1 \mathrm{c}}$ reductions of $-0.83 \%$ to $-2.07 \%$ were noted, with the highest reduction seen with combination therapy of sitagliptin $100 \mathrm{mg}$ plus metformin $2 \mathrm{mg}$ /day. Sitagliptin $100 \mathrm{mg}$ monotherapy was associated with a $-0.8 \%$ reduction in $\mathrm{HbA}_{1 \mathrm{c}}$ from baseline. The treatment was well tolerated, with hypoglycemia rates similar to those seen with placebo. Metformin-treated patients had increased gastrointestinal side effects as expected.

Qi et $\mathrm{al}^{42}$ have followed up the aforementioned cohort and reported on efficacy of sitagliptin after a total of 2 years treatment. The use of sitagliptin as monotherapy and in combination with metformin contributed to substantial reductions in $\mathrm{HbA}_{1 \mathrm{c}}(-1.41 \%$ to $-1.7 \%$ reduction from baseline).

Nonaka et $\mathrm{al}^{43}$ performed a multicenter, double-blind, randomized, placebo-controlled trial in $151 \mathrm{~T} 2 \mathrm{DM}$ patients in Japan. The baseline $\mathrm{HbA}_{1 \mathrm{c}}$ was $\geq 6.5 \%$ to $10 \%$, and they were randomized to sitagliptin $100 \mathrm{mg}$ once daily or placebo for 12 weeks. The sitagliptin-treated group achieved statistically significant reduction in $\mathrm{HbA}_{1 \mathrm{c}}$ and fasting plasma glucose in comparison with placebo. There was no hypoglycemia or weight change reported with sitagliptin.
Mohan et a ${ }^{44}$ reported a randomized, placebo-controlled, double-blind study conducted on Indian, Chinese, and Korean populations. A total of 530 treatment-naïve T2DM patients with mean baseline $\mathrm{HbA}_{1 \mathrm{c}}$ of $8.7 \%$ were randomized to sitagliptin $100 \mathrm{mg}$ once daily or placebo. At the end of the 18-week trial period, the sitagliptin group achieved a statistically significantly reduction in $\mathrm{HbA}_{1 \mathrm{c}}(-1 \%)$ compared with the placebo group. Fasting and postprandial glucose reductions were also statistically significantly reduced. No hypoglycemia was reported and the drug was well tolerated.

Hanefeld et a ${ }^{45}$ conducted a multinational, double-blind, randomized, placebo-controlled, parallel-group, dose-rangefinding study. A total of 555 patients with $\mathrm{HbA}_{1 \mathrm{c}}$ ranging between $6.5 \%$ and $10.0 \%$ were randomized to one of five treatment groups: placebo; sitagliptin $25 \mathrm{mg}, 50 \mathrm{mg}$, or $100 \mathrm{mg}$ once daily; or sitagliptin $50 \mathrm{mg}$ twice daily for 12 weeks. A mean $\mathrm{HbA}_{1 \mathrm{c}}$ reduction of $-0.39 \%$ to $-0.56 \%$ was seen across all doses of sitagliptin in comparison with placebo. Fasting plasma glucose was reduced and HOMA- $\beta$ was significantly raised in the sitagliptin group, with no change in quantitative insulin sensitivity check index (QUICKI) and HOMA-IR. Sitagliptin was well tolerated and with few hypoglycemic episodes.

All these studies have shown overall improvements in glycemic control with no significant hypoglycemia. Sitagliptin can be used in selected patient groups as first-line agent or as monotherapy.

\section{Sitagliptin in combination or add-on therapy}

Sitagliptin is preferred as an add-on therapy or second-line agent in T2DM patients at risk of hypoglycemia. The risk of hypoglycemia is higher when used in combination with sulfonylurea. Hence, patients who will benefit by such a combination should be carefully selected. It can also be used in combination with thiazolidinediones and insulin. Both the American Diabetes Association (ADA) and European Association for the Study of Diabetes (EASD) have issued position statements for recommending DPP4 inhibitor use in combination with metformin and further second- or third-line agents. It is also recommended for use with basal insulin therapy. ${ }^{46}$

\section{With metformin}

Charbonnel et a ${ }^{47}$ conducted a 24 -week randomized controlled study on $701 \mathrm{~T} 2 \mathrm{DM}$ patients established on metformin $\geq 1,500 \mathrm{mg} /$ day but with inadequate glycemic control $(\geq 7 \%$ to $\leq 10 \%)$. Patients were randomized to placebo 
or sitagliptin $100 \mathrm{mg} /$ day in a ratio of 1:2 for 24 weeks. Sitagliptin use was associated with a significant reduction in $\mathrm{HbA}_{1 \mathrm{c}}$ (mean $-0.65 \%$ ) in comparison with placebo (mean $-0.02 \%$ ). Apart from improved glycemic control, sitagliptin use resulted in significant increase in markers for $\beta$-cell function (fasting insulin, fasting $\mathrm{C}$-peptide, homeostasis model assessment of $\beta$-cell function, and QUICKI). The fasting proinsulin/insulin ratio was reduced by the end of the trial, and a small but statistically significant improvement was noted in the lipid profile with sitagliptin. Hypoglycemia was similar in both groups. However, nasopharyngitis was higher with sitagliptin.

Scott et $\mathrm{al}^{48}$ have assessed the addition of sitagliptin to 273 T2DM patients established on only metformin $\geq 1,500 \mathrm{mg} /$ day but with inadequate glycemic control (7\%-11\%). They were randomized to placebo, sitagliptin $100 \mathrm{mg}$, or rosiglitazone $8 \mathrm{mg}$ in a 1:1:1 ratio and evaluated for outcomes after 18 weeks. The improvement in glycemic control was similar in the sitagliptin and glitazone groups $(-0.79 \%$ vs $-0.73 \%)$. However, weight gain was seen in $21 \%$ of the glitazone group compared with $2 \%$ with sitagliptin. Hypoglycemia was similar between all intervention groups. Currently, pioglitazone is the only glitazone being actively used, and it may be unfair to assume similar results with this agent.

Nauck et $\mathrm{al}^{49}$ conducted a 52-week noninferiority trial comparing the addition of sitagliptin $100 \mathrm{mg} /$ day $(\mathrm{n}=588)$ or glipizide $5 \mathrm{mg} /$ day $(\mathrm{n}=584$, with dose titration to maximum $20 \mathrm{mg} /$ day) to patients established on metformin $\geq 1,500 \mathrm{mg} /$ day but with inadequate glycemic control $(\geq 6.5 \%$ to $\leq 10 \%)$. The mean $\mathrm{HbA}_{1 \mathrm{c}}$ of the cohort at baseline was $7.5 \%$, and at the end of the trial, both the groups showed a reduction of $-0.67 \%$ in $\mathrm{HbA}_{1 \mathrm{c}}$. The trial achieved its primary goal of establishing that sitagliptin is noninferior to glipizide in achieving glycemic control, but glipizide was associated with a significantly higher rate (32\%) of hypoglycemic events compared with very few $(2 \%)$ with sitagliptin. In addition, sitagliptin did not cause weight gain as glipizide did, and it actually contributed to weight loss $(-1.5 \mathrm{~kg}$ from baseline). This trial was continued for a total of 2 years, the beneficial effects of sitagliptin persisted, and it was well tolerated. $\beta$-cell function was preserved with sitagliptin as opposed to a decrease in the glipizide group. ${ }^{50}$

Lim et $\mathrm{al}^{51}$ assessed the efficacy of adding combination therapy of metformin and sitagliptin to drug-naïve T2DM patients with low $\beta$-cell function. They noted significant improvement in $\mathrm{HbA}_{1 \mathrm{c}}$ from baseline (from 8.7\% $\pm 1.4 \%$ to $7.2 \% \pm 1.3 \%$ ). Fasting plasma glucose and markers of $\beta$-cell function also improved, suggesting beneficial effects of adding sitagliptin as initial therapy.

Pérez-Monteverde et $\mathrm{al}^{52}$ have conducted an interesting study to demonstrate the beneficial effects of sitagliptin and metformin combinations when compared with pioglitazone alone. They randomized 492 treatment-naïve T2DM patients with baseline $\mathrm{HbA}_{1 \mathrm{c}}$ of $7 \%-12.5 \%$ in the ratio of $1: 1$ to either sitagliptin $100 \mathrm{mg}$ once daily or pioglitazone $15 \mathrm{mg}$ (dose increased to $30 \mathrm{mg}$ after 6 weeks). After 18 weeks of initial treatment, the sitagliptin group was switched to a combination of sitagliptin $50 \mathrm{mg}$ and metformin $1 \mathrm{mg}$ twice daily (dose titrated upwards over 4 weeks). The pioglitazone group increased the dose to $45 \mathrm{mg} /$ day. They found that in the initial 18-week monotherapy period, the $\mathrm{HbA}_{1 \mathrm{c}}$ reduction in both groups was similar. However, with the addition of metformin to sitagliptin in the second phase of the study, there was numerically improved $\mathrm{HbA}_{1 \mathrm{c}}$, fasting glucose, and postprandial glucose levels in this combination group. The hypoglycemic events were low in both groups and numerically similar. Weight loss was noted in the sitagliptin/metformin combination as opposed to weight gain in the pioglitazone group.

Olansky et $\mathrm{al}^{53}$ have reported on a trial in which an initial fixed-dose combination of metformin and sitagliptin was compared with metformin alone and following addition of other oral hypoglycemic agents. A total of $8.8 \%$ in the fixed drug group and $16.7 \%$ of the metformin alone group needed an additional oral hypoglycemic agent. The fixed combination group showed a statistically significant reduction in $\mathrm{HbA}_{1 \mathrm{c}}$ compared with the initial metformin only group (leastsquares mean change $-2.3 \%$ vs $-1.8 \%$, respectively). The target $\mathrm{HbA}_{1 \mathrm{c}}$ of $<7 \%$ was reached by a significantly higher proportion of patients in the sitagliptin and metformin combination group. This study has shown advantages of initial combination therapy over monotherapy.

\section{With sulfonylureas}

Hermansen et $\mathrm{al}^{36}$ have studied the efficacy of the addition of sitagliptin $100 \mathrm{mg} /$ day or placebo to $441 \mathrm{~T} 2 \mathrm{DM}$ patients on glimepiride $\geq 4 \mathrm{mg}$ /day monotherapy $(\mathrm{n}=212)$ or glimepiride $\geq 4 \mathrm{mg} /$ day with metformin $\geq 1,500 \mathrm{mg}$ /day $(\mathrm{n}=229)$. The cohort had inadequate glycemic control $\left(\geq 7.5 \%\right.$ to $\leq 10.5 \%$ ) at baseline, and the mean $\mathrm{HbA}_{1 \mathrm{c}}$ was $8.34 \%$. Members of the study population who exceeded the predetermined upper limits of glycemic control were offered pioglitazone as rescue therapy. After 24 weeks, the mean $\mathrm{HbA}_{1 \mathrm{c}}$ reduced with sitagliptin was $-0.74 \%$ compared with placebo. Patients on sitagliptin and glimepride plus metformin had a drop of $0.89 \%$ compared with a reduction 
of $0.57 \%$ in the sitagliptin plus glimepiride group. The addition of sitagliptin improved fasting and postprandial blood glucose significantly; markers of $\beta$-cell function were also improved at the end of 24 weeks. Hypoglycemia rates were significantly higher in the sitagliptin group compared with placebo, consistent with the use of a sulfonylurea.

\section{With pioglitazone}

Rosenstock et al ${ }^{54}$ conducted a 24-week multicenter, randomized, double-blind, placebo-controlled, parallel-group study to assess the efficacy of adding sitagliptin $100 \mathrm{mg}$ versus placebo to T2DM patients established on pioglitazone $30-45 \mathrm{mg} /$ day. In the 8 to 14 -week pretrial period, the participants who were on different antihyperglycemics were changed to pioglitazone and dose titrated to $30-45 \mathrm{mg}$ /day. Patients were randomized in a 1:1 ratio to receive sitagliptin $100 \mathrm{mg}(\mathrm{n}=175)$ or placebo $(\mathrm{n}=178)$ over the next 24 weeks. The primary end point was improvement in $\mathrm{HbA}_{1 \mathrm{c}}$ from baseline. The secondary end points were change in fasting plasma glucose, effect on markers of $\beta$-cell function, and the need for rescue metformin therapy. The mean baseline $\mathrm{HbA}_{1 \mathrm{c}}$ was $8.1 \%$ in the sitagliptin group versus $8 \%$ in the placebo group. At the end of 24 weeks, significant $\mathrm{HbA}_{1 \mathrm{c}}$ reductions (least-squares mean change of $-0.70 \%$ ) were noted with sitagliptin. Mean $\mathrm{HbA}_{1 \mathrm{c}}$ values at the end point were $7.2 \%$ (0.9) and 7.8\% (1.1) in the sitagliptin and placebo treatment groups, respectively. Sitagliptin was well tolerated with no significant hypoglycemia and remained weight neutral.

\section{With metformin and glitazones as triple therapy}

According to the current guidelines, DPP-4 inhibitors can be introduced as a monotherapy or add-on therapy quite early in the treatment plan.

Arjona Ferreira et $\mathrm{al}^{55}$ conducted a trial adding in sitagliptin to ongoing treatment with metformin ( $\geq 1,500 \mathrm{mg} /$ day) and rosiglitazone ( $\geq 4 \mathrm{mg} /$ day). A total of 278 patients were randomized to sitagliptin $100 \mathrm{mg}$ /day or placebo in a 2:1 ratio. At the end of 18 weeks, patients treated with sitagliptin resulted in an average $0.9 \%$ reduction in $\mathrm{HbA}_{1 \mathrm{c}}$ compared with baseline. Patients with higher $\mathrm{HbA}_{1 \mathrm{c}}$ at baseline showed greater reductions. Fasting plasma glucose, 2-hour postprandial glucose, and markers of $\beta$-cell function were significantly improved at the end of study when compared with placebo.

Fonseca et $\mathrm{al}^{56}$ conducted a randomized, placebocontrolled, double-blind study in 313 T2DM patients with inadequately controlled $\mathrm{HbA}_{1 \mathrm{c}}(\geq 7.5 \%$ to $\leq 11 \%)$ on metformin $\geq 1,500 \mathrm{mg} /$ day and pioglitazone $\geq 30 \mathrm{mg} /$ day.
They were randomized to sitagliptin $100 \mathrm{mg}$ once daily or placebo. The addition of sitagliptin resulted in a significant reduction in $\mathrm{HbA}_{1 \mathrm{c}}$ compared with placebo. It was well tolerated with few hypoglycemic episodes in both arms of the study.

\section{Sitagliptin and CKD}

Diabetes is the most common cause of CKD. This important and inevitable complication in most of the poorly controlled T2DM patients poses therapeutic challenges. The risk of hypoglycemia with sulfonylureas and insulin is higher in this group. Sitagliptin is licensed to be used with appropriate dose reductions.

Bergman et $\mathrm{al}^{57,58}$ have studied the effect of renal insufficiency on the pharmacokinetics of sitagliptin in a Phase III trial. The effect of a single oral dose of sitagliptin $50 \mathrm{mg}$ was evaluated in various degrees of renal insufficiency ( $\mathrm{n}=6$ in each group): mild (creatinine clearance $[\mathrm{CrCl}]$, $50-80 \mathrm{~mL} / \mathrm{min})$, moderate $(\mathrm{CrCl}, 30-50 \mathrm{~mL} / \mathrm{min})$, and severe $(\mathrm{CrCl},<30 \mathrm{~mL} / \mathrm{min})$. Patients with end-stage renal failure on hemodialysis received single-dose sitagliptin $50 \mathrm{mg}$ and had dialysis 4 hours postdose. After a washout period of 1 week, the same group of ESRD patients received a single dose of sitagliptin $50 \mathrm{mg}$, and hemodialysis was performed 48 hours later. The control group was subjects with normal renal function.

The area under the curve (AUC) for sitagliptin was less than two times normal in mild renal impairment, which was acceptable according to the predetermined value. In patients with CKD stages 3-5, including those on hemodialysis, plasma AUC levels were increased by approximately 2.3-4.5 times. This also corresponded to an increased maximum plasma concentration $\left(\mathrm{C}_{\max }\right)$ and an increased terminal half-life of up to 22.5 hours with severe renal impairment.

During hemodialysis, $13.5 \%$ and $3.5 \%$ of sitagliptin was removed after a dialysis session 4 hours and 48 hours after oral administration, respectively. The study concluded that to achieve similar plasma concentrations of sitagliptin to those in patients without renal insufficiency, moderate renal impairment (eGFR 30-50 mL) should receive $50 \mathrm{mg} /$ day, and severe renal impairment (eGFR $<30 \mathrm{~mL}$ ) or ESRD on hemodialysis patients should receive $25 \mathrm{mg}$ /day. There is no need for reduction of dose in mild renal impairment (eGFR $>50 \mathrm{~mL}$ ). Chan et al ${ }^{59}$ conducted a 54 -week safety and efficacy trial of sitagliptin over 54 weeks in patients with CKD stages 3-5, including ESRD patients on hemodialysis. It was a randomized, double-blind, parallel-group study. 
A total of 91 patients were randomized in a 2:1 ratio to sitagliptin $(n=65)$ or the sequence of placebo (initial 12 weeks) and glipizide (from the 13 th week to 54 weeks, $\mathrm{n}=26$ ). The dose of sitagliptin was reduced to $50 \mathrm{mg} /$ day or $25 \mathrm{mg} /$ day in moderate and severe renal impairment, respectively. Glipizide was started at $2.5 \mathrm{mg}$ /day and titrated to a maximum of $20 \mathrm{mg} /$ day.

The mean baseline $\mathrm{HbA}_{1 \mathrm{c}}$ was $7.7 \%$ (range $6.2 \%-10 \%$ ) and it was reduced by $-0.6 \%$ after 12 weeks and $-0.7 \%$ after 54 weeks in the sitagliptin group. The hypoglycemia rate was significantly lower in the sitagliptin group (4.6\%) compared with the placebo/glipizide group (23.1\%). Sitagliptin was well tolerated and safe in CKD stages 3-5, including patients with ESRD on dialysis.

The largest study to date assessing the efficacy and safety of sitagliptin in patients with CKD stages 3-5 was reported recently by Arjona Ferreira et al. ${ }^{60}$ They studied a total of 426 patients randomized in a ratio of $1: 1$ to sitagliptin (50 mg/day in moderate renal impairment and $25 \mathrm{mg} /$ day in severe renal impairment) or glipizide (started at $2.5 \mathrm{mg} /$ day and titrated up to $20 \mathrm{mg}$ /day). After 54 weeks, sitagliptin was noninferior to glipizide in reducing $\mathrm{HbA}_{1 \mathrm{c}}$. There was, however, a significant difference in the incidence of hypoglycemia, with $17 \%$ in the glipizide group as opposed to $6.2 \%$ with sitagliptin. Glipizide intervention was also associated with weight gain $(1.2 \mathrm{~kg})$, whereas the sitagliptin group showed a decrease in body weight $(0.6 \mathrm{~kg})$. Hence, sitagliptin at a reduced dose was safe, well tolerated, and largely remained weight neutral.

\section{Sitagliptin and ESRD on hemodialysis}

A randomized, double-blind, parallel-arm study specifically in 129 ESRD patients on hemodialysis comparing the efficacy and safety of sitagliptin and glipizide is completed and awaiting publication. The patients were randomized $1: 1$ to either sitagliptin $25 \mathrm{mg}$ /day or glipizide $2.5 \mathrm{mg}$ titrated to a maximum of $10 \mathrm{mg}$ to avoid hypoglycemia. The primary end point was to look into improvement in $\mathrm{HbA} 1 \mathrm{c}$ at the end of 54 weeks of treatment. The least-squares mean changes in $\mathrm{HbA} 1 \mathrm{c}$ from baseline in the sitagliptin- and glipizide-treated groups were $-0.72 \%$ and $-0.87 \%$, respectively. The symptomatic hyperglycemia rate was $6.3 \%$ with sitagliptin and $10.8 \%$ with glipizide. Severe hypoglycemia was significantly more frequent with glipizide $(7.7 \%)$, there being no episodes with sitagliptin. Sitagliptin was well tolerated at this dose, and, overall, adverse events and discontinuation rates were similar between the therapies. ${ }^{61}$
The results until now are convincing enough to suggest the safety of sitagliptin use in CKD with appropriate dose adjustments. Hypoglycemia rates were significantly less when compared with sulfonylureas.

\section{Use of sitagliptin and effect on clinical outcomes}

The cornerstone of diabetes management is to achieve good glycemic control, which will lead to beneficial cardiovascular outcomes. Some studies that have evaluated this have suggested that cardiovascular morbidity is reduced with use of DPP-4 inhibitors. A meta-analysis of 18 randomized studies, which included 4,998 patients on DPP-4 inhibitors, was compared with a comparator group of 3,456 on other oral agents. The median duration of these studies was 46 weeks. The relative risk for any cardiovascular event was 0.48 and for nonfatal myocardial infarction was 0.40 . This metaanalysis concluded that DPP-4 inhibitors possibly decrease cardiovascular end points. ${ }^{62}$

However, a large, retrospective, population-based cohort study $(n=72,738)$ analyzed whether sitagliptin $(n=8,032)$ use offered any benefit in cardiovascular outcomes or allcause mortality when compared with other oral antidiabetic agents $(n=64,806)$. The study showed no difference in the outcome between the two groups. ${ }^{63}$ The use of DPP-4 inhibitors is only recent, and long-term follow-up studies are needed to shed more light on cardiovascular outcomes.

\section{Conclusion}

Sitagliptin was the first DPP-4 inhibitor to be used in clinical practice, being licensed in 2006. The clinical experience of its use up until now has shown it to be beneficial in improving glycemic control as a monotherapy or as an add-on to metformin, pioglitazone, or sulfonylurea. It has also proved effective in triple therapy. The low risk of hypoglycemia and its weight-neutral properties makes it a preferred choice compared with sulfonylurea or thiazolidinediones in many scenarios. It is approved to be used with insulin and, as recognized, the hypoglycemia risk is higher with this combination, which can be avoided by insulin dose titration.

The most important recent progress is the use of sitagliptin in CKD, including ESRD patients on hemodialysis. The majority of sitagliptin is excreted unchanged following glomerular filtration. Hence, there is the potential for accumulation of drug in CKD. With appropriate reduction of its dose (25-50 mg/day), it has been shown to be safe and effective in achieving reduction in $\mathrm{HbA}_{1 \mathrm{c}}$ in this group. 


\section{Disclosure}

$\mathrm{SC}$ Bain has received honoraria, teaching and research sponsorship from the following: Abbott, Astra-Zeneca, Boehringer Ingelheim, BMS, Diartis, Eli Lilly, GlaxoSmithKline, Merck Sharp \& Dohme, Novartis, Novo Nordisk, Pfizer, Roche, Sanofi-aventis, Schering-Plough, Servier \& Takeda. The authors report no other conflicts of interest in this work.

\section{References}

1. Diabetes UK [homepage on the Internet]. Available from http://www. diabetes.org.uk. Accessed July 1, 2013.

2. González EL, Johansson S, Wallander MA, Rodríguez LA. Trends in the prevalence and incidence of diabetes in the UK: 1996-2005. J Epidemiol Community Health. 2009;63(4):332-326.

3. National Diabetes Information Clearinghouse (NDIC). National Diabetes Statistics, 2011. Available from: http://diabetes.niddk.nih. gov/dm/pubs/statistics/. Accessed July 1, 2013.

4. Nathan DM, Buse JB, Davidson MB, et al; American Diabetes Association; European Association for Study of Diabetes. Medical management of hyperglycemia in type 2 diabetes: a consensus statement of the American Diabetes Association and the European Association for the Study of Diabetes. Diabetes Care. 2009;32: 193-203.

5. National Institute for Health and Care Excellence (NICE). CG87 Type 2 diabetes - newer agents (a partial update of CG66): short guideline. Available from: http://www.nice.org.uk/nicemedia/ live/12165/44318/44318.pdf. Accessed July 1, 2013.

6. National Kidney Foundation. KDOQI clinical practice guideline for diabetes and CKD: 2012 update. Am J Kidney Dis. 2012;60(5): 850-886.

7. National Institute for Health and Care Excellence (NICE). CG73 Chronic kidney disease: early identification and management of chronic kidney disease in adults in primary and secondary care. Available from: http://www.nice.org.uk/Guidance/CG73. Accessed July 1, 2013.

8. Hallan SI, Coresh J, Astor BC, et al. International comparison of the relationship of chronic kidney disease prevalence and ESRD risk. J Am Soc Nephrol. 2006;17(8):2275-2284.

9. Coresh J, Astor BC, Greene T, Eknoyan G, Levey AS. Prevalence of chronic kidney disease and decreased kidney function in the adult US population: Third National Health and Nutrition Examination Survey. Am J Kidney Dis. 2003;41(1):1-12.

10. Haroun MK, Jaar BG, Hoffman SC, Comstock GW, Klag MJ, Coresh J. Risk factors for chronic kidney disease: a prospective study of 23,534 men and women in Washington County, Maryland. J Am Soc Nephrol. 2003;14(11):2934-2941.

11. New JP, Middleton RJ, Klebe B, et al. Assessing the prevalence, monitoring and management of chronic kidney disease in patients with diabetes compared with those without diabetes in general practice. Diabet Med. 2007;24(4):364-369.

12. Hippisley-Cox J, Coupland C. Predicting the risk of chronic kidney disease in men and women in England and Wales: prospective derivation and external validation of the QKidney Scores. BMC Fam Pract. 2010;11:49.

13. United States Renal Data System. USRDS 2007 annual data report. Bethesda, MD: National Institute of Diabetes and Digestive and Kidney Diseases, National Institutes of Health, US Department of Health and Human Services; 2007.

14. Tonelli M, Muntner P, Lloyd A, et al; Alberta Kidney Disease Network. Using proteinuria and estimated glomerular filtration rate classify risk in patients with chronic kidney disease. A cohort study. Ann Intern Med. 2011;154:12-21.

15. Kidney Disease Improving Global Outcomes (KDIGO). 2012 clinical practice guidelines for the evaluation and management of chronic kidney disease. Kidney Int Suppl. 2013;3:1-150.
16. Liang J, Leung KK, Lam SY, Leung PS. Combined treatment with a dipeptidyl peptidase-IV inhibitor (sitagliptin) and an angiotensin II type 1 receptor blocker (losartan) promotes islet regeneration via enhanced differentiation of pancreatic progenitor cells. Diabetes Obes Metab. 2012;14(9):842-581.

17. Brazg R, Xu L, Dalla Man C, Cobelli C, Thomas K, Stein PP. Effect of adding sitagliptin, a dipeptidylpeptidase-4 inhibitor, to metformin on 24-h glycemic control and beta-cell function in patients with type 2 diabetes. Diabet Obes Metab. 2007;9:186-193.

18. Mu J, Petrov A, Eiermann GJ, et al. Inhibition of DPP-4 with sitagliptin improves glycemic control and restores islet cell mass and function in a rodent model of type 2 diabetes. Eur J Pharmacol. 2009;623:148-154.

19. Ahrén B, Winzell MS, Wierup N, Sundler F, Burkey B, Hughes TE. DPP-4 inhibition improves glucose tolerance and increases insulin and GLP-1 responses to gastric glucose in association with normalized islet topography in mice with beta-cell specific overexpression of human islet amyloid polypeptide. Regul Pept. 2007;143:97-103.

20. Williams-Herman D, Xu L, Teng R, et al. Effect of initial combination therapy with sitagliptin and metformin on $\beta$-cell function in patients with type 2 diabetes. Diabetes Obes Metab. 2012;14(1):67-76.

21. Karasik A, Aschner P, Katzeff H, Davies MJ, Stein PP. Sitagliptin, a DPP-4 inhibitor for the treatment of patients with type 2 diabetes: a review of recent clinical trials. Curr Med Res Opin. 2008;24(2): 489-496.

22. Zerilli T, Pyon EY. Sitagliptin phosphate: a DPP-4 inhibitor for the treatment of type 2 diabetes mellitus. Clin Ther. 2007;29(12): 2614-2634.

23. Drucker DJ, Nauck MA. The incretin system: glucagon-like peptide-1 receptor agonists and dipeptidyl peptidase- 4 inhibitors in type 2 diabetes. Lancet. 2006;368:1696-1705.

24. Balas B, Baig MR, Watson C, et al. The dipeptidyl peptidase IV inhibitor vildagliptin suppresses endogenous glucose production and enhances islet function after single dose administration in type 2 diabetic patients. J Clin Endocrinol Metab. 2007;92:1249-1255.

25. Ahrén B, Simonsson E, Larsson H, et al. Inhibition of dipeptidyl peptidase IV improves metabolic control over a 4 week study period in type 2 diabetes. Diabetes Care. 2002;25:869-875.

26. Bergman A, Ebel D, Liu F, et al. Absolute bioavailability of sitagliptin, an oral dipeptidyl peptidase-4 inhibitor, in an oral dipeptidyl peptidase-4 inhibitor, in healthy volunteers. Biopharm Drug Dispos. 2007;28:315-322.

27. Ahrén B. DPP-4 inhibitors. Best Pract Res Clin Endocrinol Metab. 2007;21:517-533.

28. Ahrén B. Dipeptidyl peptidase-4 inhibitors: clinical data and clinical implications. Diabetes Care. 2007;30:1344-1350.

29. Ahrén B. Clinical results of treating type 2 diabetic patients with sitagliptin, vildagliptin or saxagliptin - diabetes control and potential adverse events. Best Pract Res Clin Endocrinol Metab. 2009;23:487-498.

30. JANUVIA (sitagliptin) [prescribing information]. Whitehouse Station, NJ: Merck and Co, Inc.

31. Herman GA, Stevens C, Van Dyck K, et al. Pharmacokinetics and pharmacodynamics of sitagliptin, an inhibitor of dipeptidyl peptidase IV, in healthy subjects: results from two randomized, double-blind, placebo-controlled studies with single oral doses. Clin Pharmacol Ther. 2005;78:675-688.

32. Herman GA, Bergman A, Stevens C, et al. Effect of single oral doses of sitagliptin, a dipeptidyl peptidase-4 inhibitor, on incretin and plasma glucose levels following an oral glucose tolerance test in patients with type 2 diabetes. J Clin Endocrinol Metab. 2006;91:4612-4619.

33. Vincent SH, Reed JR, Bergman AJ, et al. Metabolism and excretion of the dipeptidyl peptidase 4 inhibitor [14C] sitagliptin in humans. Drug Metab Dispos. 2007;35:533-538.

34. Bergman AJ, Stevens C, Zhou Y, et al. Pharmacokinetic and pharmacodynamic properties of multiple oral doses of sitagliptin, a dipeptidyl peptidase-IV inhibitor: a double-blind randomized, placebo-controlled study in healthy male volunteers. Clin Ther. 2006;28:55-72.

35. Herman GA, Bergman A, Liu F, et al. Pharmacokinetics and pharmacodynamic effects of the oral DPP-4 inhibitor sitagliptin in middle-aged obese subjects. J Clin Pharmacol. 2006;46:876-886. 
36. Hermansen K, Kipnes M, Luo E, Fanurik D, Khatami H, Stein P; Sitagliptin Study 035 Group. Efficacy and safety of the dipeptidyl peptidase-4 inhibitor sitagliptin in patients with type 2 diabetes mellitus inadequately controlled on glimepiride alone or in combination with metformin. Diabetes Obes Metab. 2007;9:733-745.

37. Vilsbøll T, Rosenstock J, Yki-Järvinen H, et al. Efficacy and safety of sitagliptin when added to insulin therapy in patients with type 2 diabetes. Diabetes Obes Metab. 2010;12(2):167-177.

38. Aschner P, Kipnes MS, Lunceford JK, Sanchez M, Mickel C, WilliamsHerman DE. Effect of the dipeptidyl peptidase-4 inhibitor sitagliptin as monotherapy on glycemic control in patients with type 2 diabetes. Diabetes Care. 2006;29:2632-2637.

39. Raz I, Hanefeld M, Xu L, Caria C, Williams-Herman D, Khatami H. Efficacy and safety of the dipeptidyl peptidase-4 inhibitor sitagliptin as monotherapy in patients with type 2 diabetes mellitus. Diabetologia. 2006;49:2564-25671.

40. Scott R, Wu L, Sanchez M, Stein P. Efficacy and tolerability of the dipeptidyl peptidase-4 inhibitor sitagliptin as monotherapy over 12 weeks in patients with type 2 diabetes. Int J Clin Pract. 2007;61:171-180.

41. Goldstein BJ, Feinglos MN, Lunceford JK, Johnson J, WilliamsHerman DE. Effect of initial combination therapy with sitagliptin, a dipeptidyl peptidase-4 inhibitor, and metformin on glycemic control in patients with type 2 diabetes. Diabetes Care. 2007;30:1979-1987.

42. Qi DS, Teng R, Jiang M, et al. Two-year treatment with sitagliptin and initial combination therapy of sitagliptin and metformin provides substantial and durable glycemic control in patients with type 2 diabetes. Diabetologia. 2008;51:Suppl 1:S36.

43. Nonaka K, Kakikawa T, Sato A, et al. Efficacy and safety of sitagliptin monotherapy in Japanese patients with type 2 diabetes. Diabet Res Clin Pract. 2008;79:291-298.

44. Mohan V, Yang W, Son HY, et al. Efficacy and safety of sitagliptin inthe treatment of patients with type 2 diabetes in China, India and Korea. Diab Res Clin Pract. 2009;83:106-116.

45. Hanefeld M, Herman GA, Wu M, Mickel C, Sanchez M, Stein PP. Once-daily sitagliptin, a dipeptidyl peptidase-4 inhibitor, for the treatment of patients with type 2 diabetes. Curr Med Res Opin. 2007;23(6):1329-1339.

46. Inzucchi SE, Bergenstal RM, Buse JB, et al. Management of hyperglycemia in type 2 diabetes: a patient-centered approach: position statement of the American Diabetes Association (ADA) and the European Association for the Study of Diabetes (EASD). Diabetes Care. 2012;35: 1364-1379.

47. Charbonnel B, Karasik A, Liu J, Wu M, Meininger G. Efficacy and safety of the dipeptidyl peptidase-4 inhibitor sitagliptin added to ongoing metformin therapy in patients with type 2 diabetes inadequately controlled with metformin alone. Diabetes Care. 2006;29: 2638-2643.

48. Scott R, Loeys T, Davies MJ, Engel SS. Efficacy and safety of sitagliptin when added to ongoing metformin therapy in patients with type 2 diabetes. Diabetes Obes Metab. 2008;10:959-969.

49. Nauck MA, Meininger G, Sheng D, Terranella L, Stein PP. Efficacy and safety of the dipeptidyl peptidase- 4 inhibitor, sitagliptin, compared with the sulfonylurea, glipizide, in patients with type 2 diabetes inadequately controlled on metformin alone: a randomized, double-blind, non-inferiority trial. Diabet Obes Metab. 2007;9:194-205.
50. Seck T, Nauck M, Sheng D, et al. Safety and efficacy of treatment with sitagliptin or glipizide in patients with type 2 diabetes inadequately controlled on metformin: a 2-year study. Int J Clin Pract. 2010;64(5): $562-576$.

51. Lim S, An JH, Shin H, et al. Factors predicting therapeutic efficacy of combination treatment with sitagliptin and metformin in type 2 diabetic patients: the COSMETIC study. Clin Endocrinol (Oxf). 2012;77(2): 215-223.

52. Pérez-Monteverde A, Seck T, Xu L, et al. Efficacy and safety of sitagliptin and the fixed-dose combination of sitagliptin and metformin vs pioglitazone in drug-naïve patients with type 2 diabetes. Int J Clin Pract. 2011;65(9): 930-938.

53. Olansky L, Reasner C, Seck TL, et al. A treatment strategy implementing combination therapy with sitagliptin and metformin results in superior glycemic control versus metformin monotherapy due to a low rate of addition of antihyperglycemic agents. Diabetes Obes Metab. 2011;13(9):841-849.

54. Rosenstock J, Brazg RG, Andryuk PJ, Lu K, Stein P. Efficacy and safety of the dipeptidyl peptidase-4 inhibitor sitagliptin added to ongoing pioglitazone therapy in patients with type 2 diabetes: a 24-week, multicenter, randomized, double-blind, placebo- controlled, parallelgroup study. Clinical Ther. 2006;28:1556-1568.

55. Arjona Ferreira JC, Dobs A, Goldstein BJ, et al. Triple combination therapy with sitagliptin, metformin and rosiglitazone improves glycemic control in patients with type 2 diabetes. Diabetologia. 2008; 51 Suppl 1:S365.

56. Fonseca V, Staels B, Morgan JD 2nd, et al. Efficacy and safety of sitagliptin added to ongoing metformin and pioglitazone combination therapy in a randomized, placebo-controlled, 26-week trial in patients with type 2 diabetes. J Diabetes Complications. 2013;27(2): $177-183$.

57. Bergman AJ, Cote C, Yi B, et al. Effect of renal insufficiency on the pharmacokinetics of MK-0431 (sitagliptin), a selective dipeptidylpeptidase-IV (DPP-IV) inhibitor. Clin Pharmacol Ther. 2006;79:75.

58. Bergman AJ, Cote C, Yi B, et al. Effect of Renal Insufficiency on the Pharmacokinetics of Sitagliptin, a Dipeptidyl Peptidase-4 Inhibitor. Diabetes Care. 2007;30(7):1862-1864.

59. Chan JC, Scott R, Arjona Ferreira JC, et al. Safety and efficacy of sitagliptin in patients with type 2 diabetes and chronic renal insufficiency. Diabetes Obes Metab. 2008;10(7):545-555.

60. Arjona Ferreira JC, Marre M, Barzilai N, et al. Efficacy and safety of sitagliptin versus glipizide in patients with type 2 diabetes and moderate-to-severe chronic renal insufficiency. Diabetes Care. 2013;36(5):1067-1073.

61. Arjona Ferreira JC, Corry D, Mogensen CE, et al. Efficacy and safety of sitagliptin in patients with type 2 diabetes and ESRD receiving dialysis: a 54-week randomized trial. Am J Kidney Dis. 2013;61(4): 579-587.

62. Patil HR, Al Badarin FJ, Al Shami HA, et al. Meta-analysis of effect of dipeptidyl peptidase-4 inhibitors on cardiovascular risk in type 2 diabetes mellitus. Am J Cardiol. 2012;110:826-833.

63. Eurich DT, Simpson S, Senthilselvan A, Asche CV, Sandhu-Minhas JK, McAlister FA. Comparative safety and effectiveness of sitagliptin in patients with type 2 diabetes: retrospective population based cohort study. BMJ. 2013;346:2-10.

\section{Publish your work in this journal}

Drug Design, Development and Therapy is an international, peerreviewed open-access journal that spans the spectrum of drug design and development through to clinical applications. Clinical outcomes, patient safety, and programs for the development and effective, safe, and sustained use of medicines are a feature of the journal, which

\section{Dovepress}

has also been accepted for indexing on PubMed Central. The manuscript management system is completely online and includes a very quick and fair peer-review system, which is all easy to use. Visit http://www.dovepress.com/testimonials.php to read real quotes from published authors. 